\title{
Growth inhibition of Clostridium difficile by intestinal flora of infant faeces in continuous flow culture
}

\author{
TAKAKO YAMAMOTO-OSAKI, SHIGERU KAMIYA, SADAAKI SAWAMURA, MASANORI KAI \\ and ATSUSHI OZAWA*
}

Department of Infectious Diseases, Division of Host Defense Mechanism, School of Medicine, Tokai University, Bohseidai, Isehara, Japan

\begin{abstract}
Summary. Growth of Clostridium difficile was inhibited more strongly in continuous flow (CF) culture with $C$. difficile-negative faeces of infants than with $C$. difficile-positive faeces. Culture of faecal flora of infants yielded a greater variety of bacterial species in $C$. difficilenegative than in $C$. difficile-positive faeces. In the mixed $\mathrm{CF}$ culture of $C$. difficile with Enterococcus avium, Bacteroides distasonis, Eubacterium lentum, C. ramosum, C. perfringens and either Escherichia coli or Klebsiella pneumoniae isolated from $C$. difficile-negative faeces, inhibition of growth of $C$. difficile was demonstrated when the $\mathrm{pH}$ of the culture medium was decreased. Amino-acid analysis of CF cultures showed considerable utilisation of aspartic acid, serine, threonine, arginine and asparagine. A marked increase in concentrations of citrulline and ornithine was found in the culture that inhibited growth of $C$. difficile. The addition of citrulline and ornithine into a Gifu anaerobic medium (GAM) broth produced no inhibition of growth of $C$. difficile. The addition of the mixture of the depleted amino acids (aspartic acid, serine, threonine, arginine and asparagine) to the culture filtrate or adjustment of the $\mathrm{pH}$ of the culture filtrate induced considerable growth of $C$. difficile. These results suggest that the inhibition of growth of $C$. difficile may be due to consumption of amino acids by intestinal flora, and not to the presence of inhibitors produced by the intestinal flora.
\end{abstract}

\section{Introduction}

The normal flora of the intestinal tract forms a barrier against colonisation by microbial pathogens. When the intestinal flora is disturbed by antimicrobial agents, colonisation or overgrowth of bacteria resistant to the antimicrobial agents occurs. It is accepted generally that pseudomembranous colitis (PMC) associated with Clostridium difficile develops in this manner. ${ }^{1-4}$ Wilson et al. ${ }^{2}$ reported that the administration of normal caecal homogenates reduced counts of viable $C$. difficile and prevented caecitis in hamsters given antibiotics. In an in-vitro model of colonisation resistance to $C$. difficile infection, growth of $C$. difficile and cytotoxin production were inhibited when faecal emulsions from healthy adults were added. ${ }^{4}$

Bacterial interference between $C$. difficile and other faecal bacteria, such as Escherichia coli, ${ }^{5}$ non-toxigenic C. difficile $e^{6-8}$ and lactobacilli ${ }^{9}$ was investigated in either continuous flow (CF) culture or an animal model with gnotobiotic mice and hamsters.

Colonisation of $C$. difficile is common in infants but very rare in adults. ${ }^{10-14}$ The mechanism by which $C$.

Received 10 March 1993; revised version accepted 5 Aug. 1993.

* Correspondence should be sent to Professor A. Ozawa. difficile colonises infants without causing symptoms, despite the presence of both toxin A (enterotoxin) and toxin B (cytotoxin) in the faeces, is still unclear. The higher infant colonisation rate is probably due to differences in the mucous membrane and its microflora at this age. ${ }^{15}$

To clarify the role of the normal intestinal flora in preventing colonisation by $C$. difficile, the effect of faecal flora of infants on the growth of $C$. difficile was studied in CF culture. The correlation between the production of volatile fatty acids and utilisation of amino acids in the culture with growth of $C$. difficile was also analysed.

\section{Materials and methods}

\section{Isolation and identification of $C$. difficile from faecal samples}

Faecal samples were collected from healthy infants under 3 years of age who lived in Azabu Infants' Home. Faeces $(0.5 \mathrm{~g})$ was suspended in $4.5 \mathrm{ml}$ of anaerobic diluent $\left(\mathrm{H}_{2} \mathrm{PO}_{4} 4.5 \mathrm{~g}, \mathrm{Na}_{2} \mathrm{HPO}_{4} 6.0 \mathrm{~g}\right.$, Lcysteine hydrochloride $0.5 \mathrm{~g}$, Tween $800.5 \mathrm{~g}$ and agar $0.5 \mathrm{~g}$ in $1 \mathrm{~L}$ of distilled water), homogenised, and diluted in serial 10-fold steps with the diluent. A 0.1-ml 
sample of these specimens was spread on the surface of a cycloserine-cefoxitin-fructose agar (CCFA) plate. The CCFA plate modified by Nakamura et al. ${ }^{16}$ contained cycloserine $300 \mu \mathrm{g} / \mathrm{ml}$, cefoxitin $10 \mu \mathrm{g} / \mathrm{ml}$ and sodium taurocholate $1 \mathrm{mg} / \mathrm{ml}$ (Difco) in $C$. difficile Agar Base (Oxoid) supplemented with egg yolk $5 \%$. The inoculated plate was incubated at $37^{\circ} \mathrm{C}$ for 3 days in an anaerobic chamber containing an atmosphere of $\mathrm{H}_{2} 10 \%, \mathrm{CO}_{2} 10 \%$ and $\mathrm{N}_{2} 80 \%$. Isolates were subcultured on to Gifu Anaerobic Medium (GAM) agar (Nissui Chemical Co., Tokyo, Japan) and the pure cultures obtained were assayed for biochemical characteristics. They were identified according to morphology by Gram's staining, biochemical characteristics and fermentation products determined by gas chromatography. Cytotoxicity of C. difficile isolates was assayed according to the method described previously. ${ }^{16}$

\section{Continuous flow (CF) culture}

Faecal specimens $(0 \cdot 5-1.0 \mathrm{~g})$ for CF culture were suspended in five times their weight of GAM broth and kept at $-80^{\circ} \mathrm{C}$ until use. Three $C$. difficile-positive faecal samples and four $C$. difficile-negative faecal samples were used in this study. One $\mathrm{ml}$ of the faecal suspension was inoculated into the culture vessel containing $100 \mathrm{ml}$ of GAM broth under anaerobic conditions at $37^{\circ} \mathrm{C}$. The dilution rate was $0 \cdot 05 / \mathrm{h}$. For the CF culture of the $C$. difficile-positive faecal sample, a $C$. difficile strain that had been isolated from the same faecal sample and pre-cultured in another CF culture for 3 days was inoculated 10 days after the inoculation of faecal flora. One $\mathrm{ml}$ of $10^{3}$-fold diluted $C$. difficile culture, which had been pre-cultured in GAM broth at $37^{\circ} \mathrm{C}$ for $18 \mathrm{~h}$, was inoculated into the CF culture, resulting in an initial count of $10^{5} \mathrm{cfu} / \mathrm{ml}$. For the $\mathrm{CF}$ culture of the $C$. difficile-negative faecal sample, $C$. difficile strain $\mathrm{N} 8$ isolated from one faecal sample was inoculated in the same manner 10 days after the inoculation of faecal flora as described above. One $\mathrm{ml}$ of the culture was sampled at an appropriate time after the inoculation for viable counts of $C$. difficile and other bacteria. On days 0,10 and 17, $5 \mathrm{ml}$ of the culture were collected to analyse fermentation products and identify the bacterial flora.

CF cultures of several bacterial strains were performed in the same manner as described above. In the mixed culture of anaerobes and aerobes, the aerobes were inoculated 1 day after the inoculation of the anaerobes. Toxigenic ( $C$. difficile T-C-2 and T-C-9) or non-toxigenic ( $C$. difficile $\mathrm{N} 8$ and N13) strains that had been isolated from faecal samples and pre-cultured in another CF culture for 3 days, were inoculated 10 days after the inoculation of the aerobes. Samples $(5 \mathrm{ml})$ of the culture were collected to analyse both fermentation products and amino acids on days 0 and 7 after the inoculation of $C$. difficile. One $\mathrm{ml}$ of the culture was sampled at an appropriate time for viable counts and determination of cytotoxic activity.

\section{Quantitative study of bacterial flora and $C$. difficile}

A $0.1 \mathrm{ml}$ sample of the culture diluted 10 -fold serially with the anaerobic diluent was spread on the surfaces of various selective media. DeoxycholateHydrogen sulphide-Lactose (DHL) Agar (Nissui Chemical Co.) and Phenylethyl alcohol (PEA) Agar (Difco) supplemented with horse blood $5 \%$ were used for the selection of aerobes. Candida GS Agar (Nissui Chemical Co.) was used for the selection of Candida spp. Cultures were incubated aerobically at $37^{\circ} \mathrm{C}$ for 2 days. GAM agar supplemented with gentamicin, PEA agar, Veillonella Agar (Difco) supplemented with both kanamycin and neomycin, Fusobacterium (FM) Agar (Nissui Chemical Co.), Eugon Agar (Difco) supplemented with either kanamycin and vancomycin with horse blood $5 \%$ or rifampicin with horse blood $5 \%$, were used for the isolation of anaerobic intestinal flora. Cultures were incubated anaerobically at $37^{\circ} \mathrm{C}$ for 3 days. The colonies were counted and expressed as $\mathrm{cfu} / \mathrm{g}$ of faeces or $\mathrm{cfu} / \mathrm{ml}$. Anaerobes were identified according to the method described above. Aerobes were identified by API 20E, API Staph, API Strep and API 20C Aux (API system S.A., Montaneu Vercieu, France).

\section{Gas chromatography of the fermentation products}

Cultures were stored at $-80^{\circ} \mathrm{C}$ for analysis of volatile fatty acids (VFAs) by gas-liquid chromatography (model 263-70, Hitachi Ltd, Tokyo, Japan): $0.2 \mathrm{ml}$ of $\mathrm{H}_{2} \mathrm{SO}_{4} 50 \%, \mathrm{NaCl} 0.4 \mathrm{~g}, 1 \mathrm{ml}$ of ethylether and $0.1 \mathrm{ml}$ of $5 \mathrm{~mm} 2$ methyl-n-valeric acid (Tokyo kasei, Tokyo, Japan) used for the internal standard, were added to $1 \mathrm{ml}$ of the culture. The ethylether and the culture were mixed in a culture tube by inverting the tube 100 times. The mixture was centrifuged at $3000 \mathrm{rpm}$ for $3 \mathrm{~min}$. The ether layer was pipetted into another test tube to which anhydrous $\mathrm{CaCl}_{2}(c .0 .5 \mathrm{~g})$ was added and the test tube was left to stand for $5 \mathrm{~min}$. The ether extract was then discarded into another culture tube and placed at $-80^{\circ} \mathrm{C}$ until injection. The extract was injected on to a gas chromatography column $(2 \mathrm{~m} \times 5 \mathrm{~mm})$ packed with PolyesterNF $15 \%$ on Neosorb NS 60/80 (Chromato Research Ltd, Kanagawa, Japan). The flow rate of carrier gas $\left(\mathrm{N}_{2}\right)$ was $30 \mathrm{ml} / \mathrm{min}$. The injection temperature was $200^{\circ} \mathrm{C}$ and the temperatures of the column and detector were $150^{\circ} \mathrm{C}$ and $200^{\circ} \mathrm{C}$, respectively. The VFA concentration of each peak was quantified by comparison with the peaks of standard VFA solution and was expressed as micro-equivalents/ml of culture.

\section{Amino-acid analysis}

The CF culture medium, GAM broth and the culture harvested at various times after inoculation were treated with the same volume of sulphosalicylic acid dihydrate $5 \%$ solution to remove protein. After the treatment, the compositions of amino acids in 


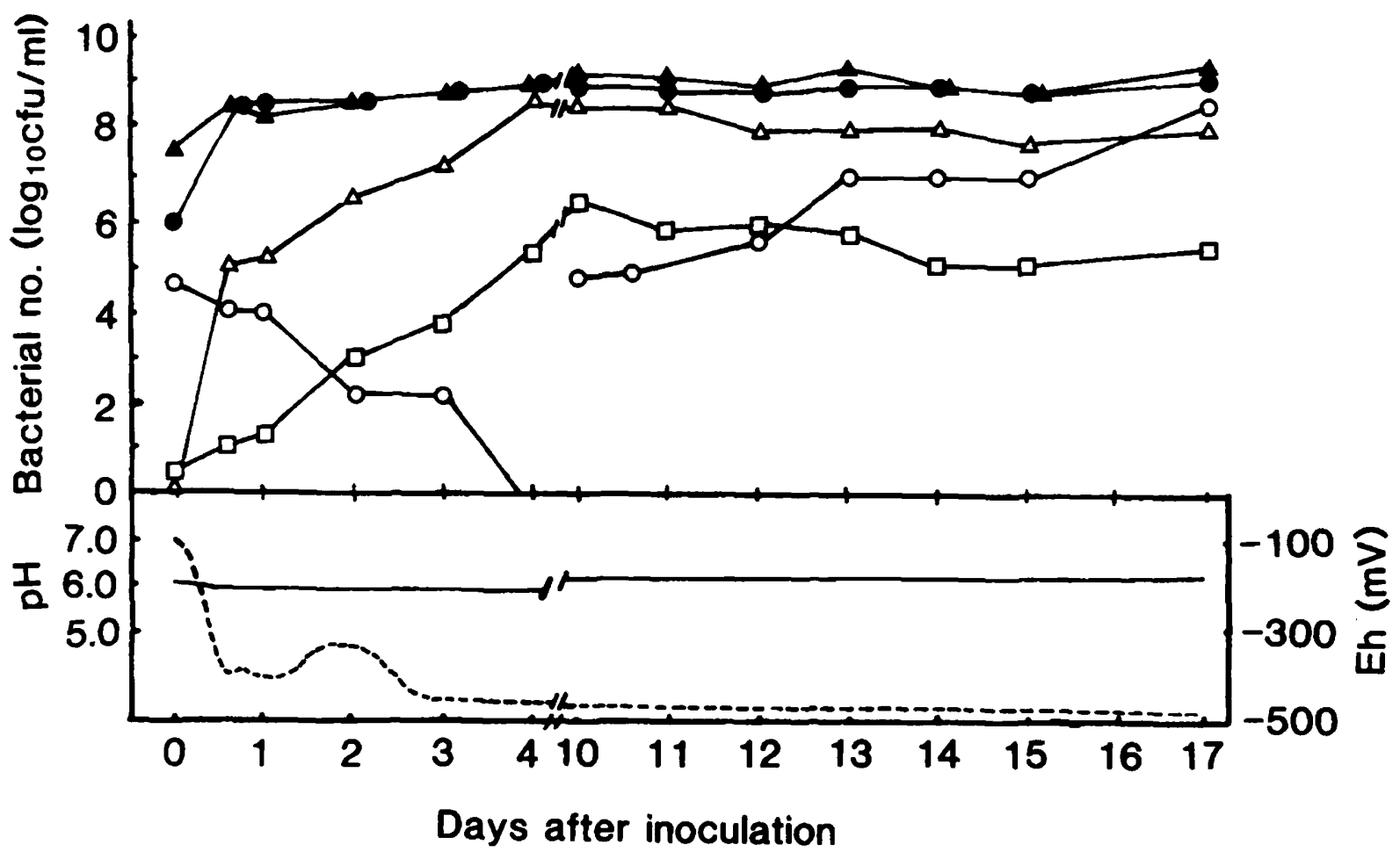

Fig. 1. Growth of $C$. difficile strain N8 in anaerobic $\mathrm{CF}$ culture with a $C$. difficile-positive faecal specimen of an infant: viable counts of C. difficile $(\bigcirc)$, enterococci $(\bullet)$, enterobacteriaceae $(\triangle)$, total obligative anaerobes $(\boldsymbol{\Delta})$ and Can. albicans $(\square)$ were determined; redox potential $(\mathrm{Eh})(----)$ and $\mathrm{pH}(-)$ were also measured.

these samples were analysed by a rapid amino acid analyser (Model 835, Hitachi).

\section{Preparation of dialysed culture filtrate of faecal bacterial strains}

Enterococcus avium, Escherichia coli, Bacteroides distasonis, Eubacterium lentum, C. ramosum and $C$. perfringens were inoculated into $80 \mathrm{ml}$ of GAM broth in a cellophane dialysis tube suspended in $120 \mathrm{ml}$ of GAM broth; 7 days after inoculation, the outer culture filtrate $(120 \mathrm{ml})$ was collected. Five amino acidsaspartic acid, serine, threonine, arginine and asparagine - were added to the dialysed culture filtrate to give the same concentration of the amino acids as GAM broth, which was quantified by amino acid analysis.

\section{Results}

\section{Incidence of $C$. difficile in the faecal samples}

Faecal samples from 62 healthy infants were tested for $C$. difficile. Five infants from whom $C$. difficile was isolated were examined again 1 year after the first investigation. Two of the five infants had $C$. difficilepositive faeces again and three infants gave negative results. A high isolation frequency of $C$. difficile $(65 \%)$ was observed in babies $<1$ year old ( 20 faecal samples); 23 and $33 \%$ of faecal samples from 1-2year-old ( 35 samples) and 2-3-year-old (12 samples) children respectively, were positive for $C$. difficile. C. difficile was isolated from $25(37 \%)$ samples out of a total of 67 faecal samples examined. Of 17 strains of C. difficile tested for toxigenicity, 11 strains were cytotoxic.

Growth of $C$. difficile in the anaerobic $C F$ culture with faecal flora

When a $C$. difficile-positive faecal specimen was inoculated into $\mathrm{CF}$ culture, considerable growth of faecal flora was observed (fig. 1). The stable growth of faecal flora $\left(c .10^{8-9} \mathrm{cfu} / \mathrm{ml}\right)$ continued during the experimental period. However, $C$. difficile did not grow and was washed out. The number of $C$. difficile was $10^{2} \mathrm{cfu} / \mathrm{ml}$ at 3 days after the inoculation of faeces and no $C$. difficile was subsequently detected 4 days after inoculation. When the $\mathrm{N} 8$ strain of $C$. difficile that had been isolated from the same faecal specimen was inoculated again into the $\mathrm{CF}$ culture of faecal flora 10 days after inoculation of the faeces, the number of C. difficile 2-7 days after the second inoculation was found to be between $10^{5.5}$ and $10^{7 \cdot 6} \mathrm{cfu} / \mathrm{ml}$.

When a $C$. difficile-negative faecal specimen was inoculated, it appeared that the total counts of faecal flora reached $>10^{9} \mathrm{cfu} / \mathrm{ml}$ after 1 day (fig. 2). When the $C$. difficile $\mathrm{N} 8$ strain was inoculated into the $\mathrm{CF}$ culture of faecal flora 10 days after inoculation of the faeces, the N8 strain did not grow and its viable count gradually decreased.

The $\mathrm{CF}$ cultures of $C$. difficile-positive or -negative faecal samples were examined for growth of $C$. difficile 


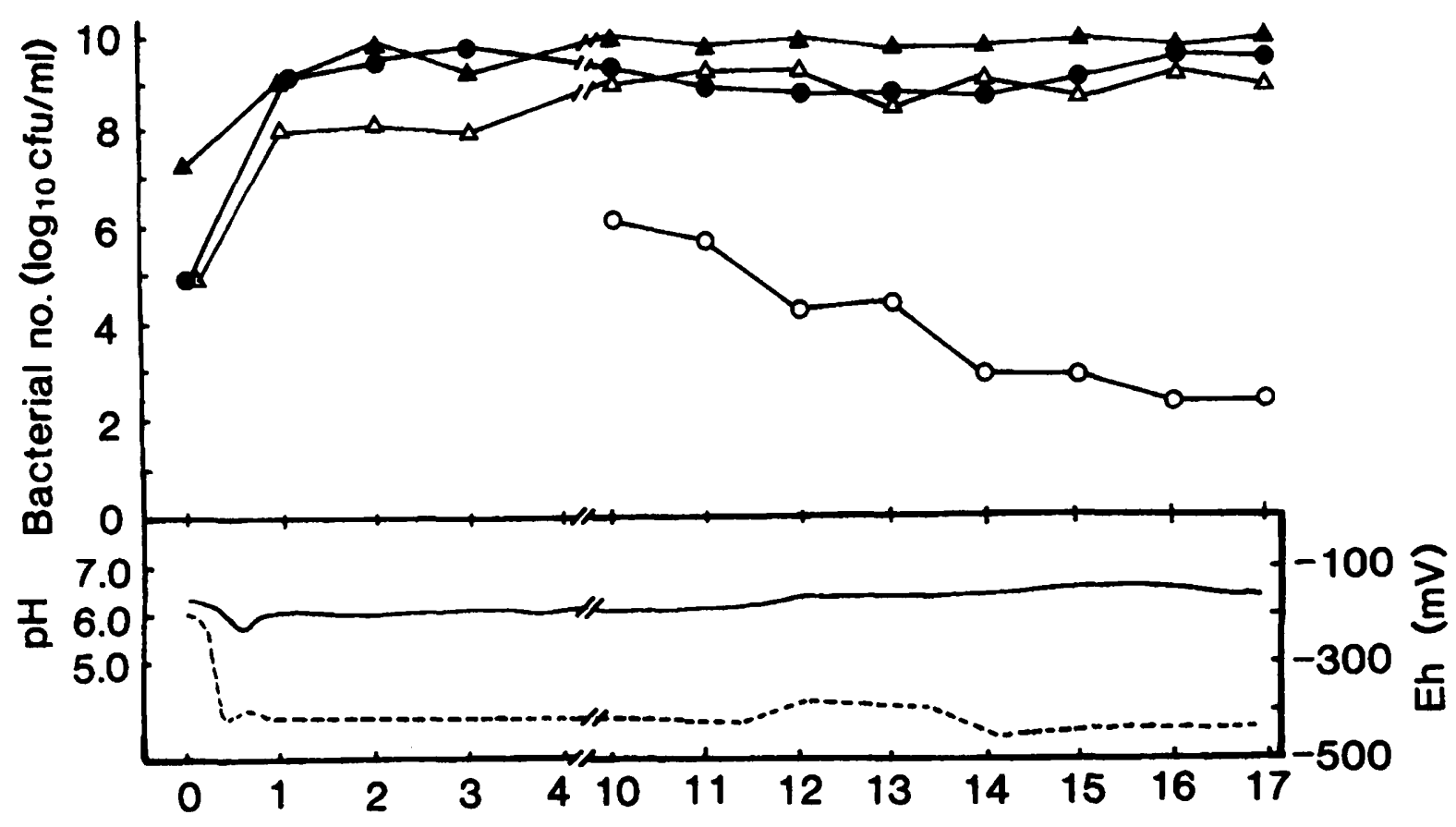

Days after inoculation

Fig. 2. Growth of $C$. difficile strain N8 in anaerobic CF culture with a $C$. difficile-negative faecal specimen from an infant: viable counts of C. difficile $(O)$, enterococci $(\Theta)$, enterobacteriaceae $(\triangle)$ and total obligative anaerobes $(\boldsymbol{\Delta})$ were determined; redox potential $(\mathrm{Eh})(-----)$ and $\mathrm{pH}(\longrightarrow)$ were also measured.

Table I. Numbers of $C$. difficile harvested 2-7 days after inoculation of $C$. difficile into $\mathrm{CF}$ cultures with various faecal samples

\begin{tabular}{|c|c|c|}
\hline $\begin{array}{l}\text { Isolation of } \\
\text { C. difficile } \\
\text { from faecal sample }\end{array}$ & $\begin{array}{l}\text { Faecal sample } \\
\text { no. }\end{array}$ & $\begin{array}{l}\text { Mean (SD) number of } C \text {. difficile } \\
\text { in } C F \text { culture }\left(\log _{10} \mathrm{cfu} / \mathrm{ml}\right)^{*}\end{array}$ \\
\hline Positive† & $\begin{array}{l}1 \\
2 \\
3\end{array}$ & $\begin{array}{l}4 \cdot 8(1 \cdot 1) \\
6 \cdot 5(0 \cdot 6) \\
6 \cdot 7(1 \cdot 0)\end{array}$ \\
\hline Negative & $\begin{array}{l}1 \\
2 \\
3 \\
4\end{array}$ & $\begin{array}{l}3.9(0 \cdot 6) \\
3 \cdot 2(1 \cdot 1) \\
2.4(1 \cdot 1) \\
6.8(0 \cdot 4)\end{array}$ \\
\hline
\end{tabular}

2-7 days after the second inoculation with $C$. difficile (table I). Generally, much higher counts of $C$. difficile were detected in the $\mathrm{CF}$ culture with $C$. difficilepositive faeces than with $C$. difficile-negative faeces.

\section{Growth of $C$. difficile in the anaerobic $C F$ culture with several intestinal strains}

The intestinal flora of the $C$. difficile-positive or -negative faeces was analysed (table II). Four $C$. difficile-negative samples had faecal flora consisting of 16-17 anaerobic species, 8-10 aerobic species and Candida albicans. In contrast, three $C$. difficile-positive samples had faecal flora consisting of 7-11 anaerobic species, 4-5 aerobic species and Can. albicans.
The effect of a mixed culture of faecal bacterial strains such as $C$. perfringens, E. coli, Ent. avium, Klebsiella pneumoniae, C. ramosum, B. distasonis and $E$ u. lentum on the growth of $C$. difficile strain N8 was examined (table III). These bacterial strains were all isolated from the $C$. difficile-negative faecal samples. In the mixed CF culture of $C$. difficile with Ent. avium, $B$. distasonis, Eu. lentum, C. ramosum, C. perfringens, and either $E$. coli or $K$. pneumoniae, considerable inhibition of growth with a decreased $\mathrm{pH}$ of culture medium was demonstrated (statistically significant at $\mathrm{p}<0.01)$.

In several CF cultures of toxigenic or non-toxigenic $C$. difficile strains with Ent. avium, B. distasonis, Eu. lentum, C.ramosum, $C$. perfringens and either $E$. coli or 
Table II. Intestinal flora of $C$. difficile-positive or -negative faecal samples of infants during anaerobic CF culture

\begin{tabular}{|c|c|c|c|c|c|}
\hline \multicolumn{3}{|c|}{ C. difficile-negative faeces } & \multicolumn{3}{|c|}{ C. difficile-positive faeces } \\
\hline \multirow{3}{*}{ Species } & \multicolumn{2}{|c|}{ Viable count $\left(\log _{10} / \mathrm{ml}\right)$} & \multirow{3}{*}{ Species } & \multicolumn{2}{|c|}{ Viable count $\left(\log _{10} / \mathrm{ml}\right)$} \\
\hline & \multicolumn{2}{|c|}{ days after inoculation } & & \multicolumn{2}{|c|}{ days after inoculation } \\
\hline & Day 0 & 17 & & Day 0 & 17 \\
\hline Ent. avium & $5 \cdot 0$ & 9.6 & Ent. avium & $6 \cdot 0$ & $9 \cdot 0$ \\
\hline E. coli & 4.9 & $8 \cdot 3$ & Ent. faecium & $5 \cdot 0$ & 8.6 \\
\hline$K$. pneumoniae & $4 \cdot 0$ & $9 \cdot 3$ & Citrobacter freundii & 0.8 & 7.8 \\
\hline S. capitis & 1.8 & $<1.0$ & $K$. pneumoniae & 0.7 & 7.5 \\
\hline Ent. faecium & $<1.0$ & $9 \cdot 7$ & & & \\
\hline Providencia rettgeri & $<1.0$ & 8.0 & & & \\
\hline Ent. faecalis & $<1.0$ & $7 \cdot 2$ & & & \\
\hline Lactococcus lactis & $<1.0$ & $7 \cdot 0$ & & & \\
\hline Can. albicans & $1 \cdot 0$ & $<1.0$ & Can. albicans & $1 \cdot 2$ & $4 \cdot 8$ \\
\hline B. distasonis & $7 \cdot 3$ & $8 \cdot 3$ & Eu. lentum & $7 \cdot 5$ & $8 \cdot 8$ \\
\hline Bif. adolescentis & $7 \cdot 0$ & 8.9 & B. distasonis & $7 \cdot 5$ & 8.0 \\
\hline Pstr. productus & 6.9 & 8.9 & Bif. adolescentis & $7 \cdot 1$ & 8.7 \\
\hline Eu. lentum & 6.7 & $9 \cdot 3$ & L. brevis & 7.0 & $<1.0$ \\
\hline B. vulgatus & 6.5 & 9.5 & B. fragilis & 6.9 & $<1.0$ \\
\hline L. acidophilus & $6 \cdot 4$ & $5 \cdot 0$ & C. paraputrificum & $6 \cdot 0$ & $<1.0$ \\
\hline C. ramosum & 5.7 & $8 \cdot 5$ & L. fermentum & 5.8 & $<1.0$ \\
\hline C. paraputrificum & $5 \cdot 3$ & $<1.0$ & Str. intermedius & $5 \cdot 0$ & $<1.0$ \\
\hline L. plantarum & $5 \cdot 3$ & $<1.0$ & C. aminovalericum & $3 \cdot 3$ & $<1.0$ \\
\hline Veillonella parvula & $5 \cdot 0$ & 8.0 & & & \\
\hline Bif. longum & 3.8 & $<1.0$ & V. parvula & 1.6 & $9 \cdot 5$ \\
\hline Fusobacterium & $2 \cdot 4$ & $<1.0$ & C. difficile & $3 \cdot 2$ & $(8 \cdot 5)$ \\
\hline $\begin{array}{l}\text { nucleatum } \\
\text { C. perfringens }\end{array}$ & $2 \cdot 3$ & $9 \cdot 4$ & & & \\
\hline Str. intermedius & $<1.0$ & $8 \cdot 5$ & & & \\
\hline L. casei subsp. & $<1.0$ & $8 \cdot 3$ & & & \\
\hline $\begin{array}{l}\text { rhamnosus } \\
\text { C. difficile }\end{array}$ & & $(2 \cdot 0)^{*}$ & & & \\
\hline
\end{tabular}

* The number in parentheses is the number of $C$. difficile strain N8 that were inoculated 10 days after inoculation of faecal sample in CF culture to give an initial count of $10^{5} \mathrm{cfu} / \mathrm{ml}$.

Table III. Effect of mixed CF culture with various bacterial strains on the growth of C. difficile strain N8

\begin{tabular}{|c|c|c|c|}
\hline \multirow{2}{*}{ Mixed CF culture } & \multirow{2}{*}{$\begin{array}{c}\text { Mean (SD) number of } C \text {. difficile } \\
\text { harvested } 2-7 \text { days } \\
\text { after inoculation } \\
\left(\log _{10} \mathrm{cfu} / \mathrm{ml}\right)\end{array}$} & \multicolumn{2}{|c|}{$\mathrm{pH}$ of the culture } \\
\hline & & Day 0 & 7 days \\
\hline $\begin{array}{l}\text { None* } \\
\text { C. perfringens } \\
\text { Ent. avium, E. coli } \\
\text { Ent. avium, } K \text {. pneumoniae, C. perfringens } \\
\text { Ent. avium, E. coli, C. perfringens }\end{array}$ & $\begin{array}{l}8 \cdot 1(0 \cdot 2) \\
7 \cdot 5(0 \cdot 3) \\
7 \cdot 4(0 \cdot 3) \\
7 \cdot 1(0 \cdot 3) \\
6 \cdot 9(0 \cdot 2)\end{array}$ & $\begin{array}{l}6 \cdot 6 \\
6 \cdot 4 \\
7 \cdot 3 \\
6 \cdot 3 \\
7 \cdot 1\end{array}$ & $\begin{array}{l}6 \cdot 3 \\
6 \cdot 3 \\
6 \cdot 6 \\
6 \cdot 6 \\
6 \cdot 5\end{array}$ \\
\hline $\begin{array}{l}\text { Ent. avium, } \text { E. coli } \\
\text { B. distasonis, Eu. lentum } \\
\text { C. ramosum, C. perfringens }\end{array}$ & $6.2(0.6)$ & $5 \cdot 4$ & $5 \cdot 4$ \\
\hline $\begin{array}{l}\text { Ent. avium, } K \text {. pneumoniae } \\
\text { B. distasonis, Eu. lentum } \\
\text { C. ramosum, C. perfringens }\end{array}$ & $5.8(0 \cdot 7)$ & $5 \cdot 5$ & 5.9 \\
\hline
\end{tabular}

${ }^{*}$ C. difficile strain $\mathrm{N} 8$ was incubated in $\mathrm{CF}$ culture for 7 days.

$K$. pneumoniae, growth of $C$. difficile 2-7 days after inoculation with $C$. difficile was also examined (table IV). Greater viable counts of $C$. difficile were detected in the $\mathrm{CF}$ culture of non-toxigenic $C$. difficile than in the $\mathrm{CF}$ culture of toxigenic $C$. difficile. In the mixed $\mathrm{CF}$ culture of the toxigenic strain T-C-9, 1-7 days after inoculation, neither $C$. difficile nor cytotoxic activity was detected. In the case of the toxigenic strain T-C-2, lower cytotoxin production with considerable inhibition of growth of $C$. difficile was detected in the culture.

Volatile fatty acids (VFAs) in mixed CF culture

VFAs in the six serial CF cultures before and after inoculation of $C$. difficile strain $\mathrm{N} 8$ were studied 
Table IV. Inhibition of growth of $C$. difficile by co-cultivation with $C$. perfringens, C. ramosum, Eu. lentum, B. distasonis, Ent. avium and E. coli

\begin{tabular}{|c|c|c|c|c|c|}
\hline \multirow{2}{*}{ Strain no. } & & \multicolumn{2}{|c|}{$\begin{array}{c}\text { Mean (SD) number of } \\
\text { C. difficile } \\
\left(\log _{10} \mathrm{cfu} / \mathrm{ml}\right)\end{array}$} & \multicolumn{2}{|c|}{$\begin{array}{l}\text { Maximum cytotoxin titre } \\
\left(\log _{2}\right)\end{array}$} \\
\hline & & $\begin{array}{c}\text { Single } \\
\mathrm{CF} \text { culture }\end{array}$ & $\begin{array}{c}\text { Mixed } \\
\text { CF culture }\end{array}$ & $\begin{array}{c}\text { Single } \\
\text { CF culture }\end{array}$ & $\begin{array}{c}\text { Mixed } \\
\text { CF culture }\end{array}$ \\
\hline Non-toxigenic & $\begin{array}{l}\text { N8 } \\
\text { N13 }\end{array}$ & $\begin{array}{l}8 \cdot 2(0.2) \\
8 \cdot 1(0 \cdot 1)\end{array}$ & $\begin{array}{l}4 \cdot 9(0 \cdot 3) \\
6 \cdot 4(0 \cdot 3)\end{array}$ & $\begin{array}{l}\text { ND } \\
\text { ND }\end{array}$ & $\begin{array}{l}\text { ND } \\
\text { ND }\end{array}$ \\
\hline Toxigenic & $\begin{array}{l}\text { T-C-2 } \\
\text { T-C-9 }\end{array}$ & $\begin{array}{l}8 \cdot 1(0 \cdot 2) \\
8 \cdot 0(0 \cdot 2)\end{array}$ & $\begin{array}{l}2 \cdot 6(0 \cdot 6) \\
\text { ND }\end{array}$ & $\begin{array}{r}13 \\
9\end{array}$ & $\begin{array}{c}4 \\
\text { ND }\end{array}$ \\
\hline
\end{tabular}

ND, not detected

Table V. Concentration of VFAs in CF culture in faecal bacterial strains before and after inoculation with $C$. difficile strain $\mathrm{N} 8$

\begin{tabular}{|c|c|c|c|c|c|c|c|c|c|c|}
\hline \multirow{3}{*}{ Mixed CF culture with } & \multicolumn{10}{|c|}{ Concentration* of VFA $(\mu \mathrm{mol} / \mathrm{ml})$} \\
\hline & \multicolumn{2}{|c|}{ Acetic acid } & \multicolumn{2}{|c|}{ Propionic acid } & \multicolumn{2}{|c|}{ Butyric acid } & \multicolumn{2}{|c|}{$i$-Caproic acid } & \multicolumn{2}{|c|}{ Total VFAs } \\
\hline & B & A & B & A & B & A & B & A & B & A \\
\hline C. perfringens & $12 \cdot 4$ & $23 \cdot 5$ & $0 \cdot 3$ & 0.4 & $19 \cdot 3$ & $23 \cdot 6$ & ND & 17.2 & $32 \cdot 0$ & $64 \cdot 7$ \\
\hline Ent. avium, E. coli & $18 \cdot 6$ & $35 \cdot 5$ & 0.5 & $0 \cdot 6$ & 0.2 & $16 \cdot 3$ & ND & $18 \cdot 8$ & $19 \cdot 3$ & $71 \cdot 2$ \\
\hline $\begin{array}{l}\text { Ent. avium, } K . \text { pneumoniae, } \\
\text { C. perfringens }\end{array}$ & $24 \cdot 2$ & $42 \cdot 9$ & 0.7 & $0 \cdot 8$ & $18 \cdot 7$ & $20 \cdot 9$ & ND & $19 \cdot 6$ & $43 \cdot 6$ & $84 \cdot 2$ \\
\hline $\begin{array}{l}\text { Ent. avium, E. coli, } \\
\text { C. perfringens }\end{array}$ & $19 \cdot 6$ & $40 \cdot 0$ & 0.6 & $0 \cdot 4$ & $11 \cdot 9$ & $20 \cdot 6$ & ND & $18 \cdot 0$ & $32 \cdot 0$ & $79 \cdot 1$ \\
\hline $\begin{array}{l}\text { Ent. avium, } E \text {. coli, } \\
\text { B. distasonis, Eu. lentum } \\
\text { C. ramosum, C. perfringens }\end{array}$ & $36 \cdot 0$ & $35 \cdot 2$ & $1 \cdot 3$ & $2 \cdot 5$ & $21 \cdot 6$ & $23 \cdot 2$ & ND & $16 \cdot 4$ & $58 \cdot 9$ & $77 \cdot 3$ \\
\hline $\begin{array}{l}\text { Ent. avium, } K . \text { pneumoniae } \\
\text { B. distasonis, Eu. lentum } \\
\text { C. ramosum, C. perfringens }\end{array}$ & $30 \cdot 1$ & $44 \cdot 6$ & 1.5 & $6 \cdot 3$ & $24 \cdot 4$ & $23 \cdot 4$ & ND & $12 \cdot 9$ & $55 \cdot 9$ & $87 \cdot 1$ \\
\hline
\end{tabular}

Concentration* of VFA in CF culture harvested before (B) and 7 days after (A) inoculation with C. difficile strain N8.

ND, not detected.

quantitatively (table V). In most samples harvested before inoculation, acetic acid was the major product, with butyric acid in second place. Statistically, the increased concentrations of acetic acid, propionic acid and total VFAs before $C$. difficile inoculation were inversely proportional to the average number of $C$. difficile harvested 2-7 days after inoculation in the six serial CF cultures. There was a significant inverse correlation between the concentrations of acetic acid, propionic acid and total VFAs before inoculation with $C$. difficile and the inhibitory effect on growth of $C$. difficile. However, no direct correlation between the concentrations of VFAs in the samples harvested after inoculation with $C$. difficile and the inhibition of growth of $C$. difficile was observed, although the concentration of iso-caproic acid was parallel to the viable count of $C$. difficile. Similar results were obtained when the toxigenic strain T-C-9 was inoculated (data not shown).

In static culture of $C$. difficile, the addition of either acetic acid or propionic acid to the high concentration detected in the mixed CF culture, did not inhibit growth of $C$. difficile at all (data not shown). However, addition of all four volatile acids (acetic, propionic, butyric and iso-caproic acids) inhibited the growth of $C$. difficile with a marked decrease in $\mathrm{pH}(\mathrm{pH} \mathrm{4.8)}$ (data not shown).

\section{Analysis of amino acids in mixed CF culture}

Concentrations of amino acids in both single $\mathrm{CF}$ culture of $C$. difficile and mixed culture of $C$. difficile with various faecal flora were analysed. Aspartic acid, citrulline, leucine, isoleucine, proline, serine and threonine were utilised well by $C$. difficile, including two toxigenic and two non-toxigenic strains, in single culture. In the mixed culture of $C$. difficile strain N8 with $C$. perfringens, $C$. ramosum, Eu. lentum, $B$. distasonis, Ent. avium and either E. coli or K. pneumoniae, complete or almost complete consumption of aspartic acid, serine, threonine, arginine and asparagine and marked increase of concentrations of citrulline and ornithine were shown before and after inoculation with $C$. difficile (table VI). Neither cit- 
Table VI. Amino-acid analysis of mixed CF culture of $C$. difficile with various bacterial strains

\begin{tabular}{|c|c|c|c|c|c|c|c|}
\hline \multirow{4}{*}{$\begin{array}{l}\text { Amino } \\
\text { acid }\end{array}$} & \multicolumn{7}{|c|}{$\begin{array}{l}\text { Relative concentration of amino acid* after } \\
\text { co-cultivation of } C \text {. difficile with }\end{array}$} \\
\hline & \multirow[t]{3}{*}{$\begin{array}{l}\text { None } \\
\text { (A) }\end{array}$} & \multicolumn{2}{|c|}{$\begin{array}{c}\text { C. perfringens } \\
\text { Ent. avium } \\
\text { E. coli }\end{array}$} & \multirow{2}{*}{\multicolumn{2}{|c|}{$\begin{array}{l}\text { C. perfringens } \\
\text { C. ramosum } \\
\text { Eu. lentum } \\
\text { B. distasonis } \\
\text { Ent. avium } \\
\text { E. coli }\end{array}$}} & \multirow{2}{*}{\multicolumn{2}{|c|}{$\begin{array}{c}\text { C. perfringens } \\
\text { C. ramosum } \\
\text { Eu. lentum } \\
\text { B. distasonis } \\
\text { Ent. avium } \\
\text { K. pneumoniae }\end{array}$}} \\
\hline & & \multirow[t]{2}{*}{ B } & \multirow[t]{2}{*}{ A } & & & & \\
\hline & & & & B & A & B & A \\
\hline Asp & 39 & $8+$ & 9 & 98 & 0 & 7 & 14 \\
\hline $\mathrm{Cit}$ & 0 & 0 & 0 & 265 & 343 & 181 & 197 \\
\hline Ile & 45 & 105 & 16 & 99 & 53 & 110 & 52 \\
\hline Leu & 10 & 95 & 8 & 88 & 33 & 96 & 38 \\
\hline Pro & 0 & 0 & 0 & 155 & 34 & 62 & 26 \\
\hline Ser & 0 & 0 & 0 & 2 & 3 & 3 & 4 \\
\hline Thr & 0 & 0 & 0 & 16 & 8 & 8 & 9 \\
\hline Arg & 111 & 53 & 65 & 0 & 0 & 0 & 0 \\
\hline Asn & 87 & 0 & 0 & 56 & 0 & 0 & 0 \\
\hline Glu & 127 & 77 & 86 & 70 & 50 & 12 & 15 \\
\hline Gly & 118 & 73 & 87 & 136 & 110 & 158 & 131 \\
\hline His & 149 & 119 & 127 & 116 & 158 & 133 & 156 \\
\hline Lys & 0 & 13 & 68 & 16 & 2 & 105 & 118 \\
\hline Met & 76 & 94 & 55 & 101 & 98 & 112 & 113 \\
\hline Phe & 81 & 92 & 71 & 77 & 82 & 81 & 85 \\
\hline Tyr & 123 & 0 & 0 & 76 & 0 & 11 & 12 \\
\hline Val & 90 & 117 & 36 & 120 & 94 & 139 & 95 \\
\hline Ala & 198 & 132 & 60 & 123 & 141 & 133 & 144 \\
\hline Orn & 186 & 130 & 102 & 1456 & 1812 & 1275 & 1534 \\
\hline Trp & 185 & 53 & 103 & 96 & 222 & 187 & 160 \\
\hline
\end{tabular}

* The concentration of each amino acid in fresh GAM broth was expressed as 100 . $\dagger$ The relative concentrations of each amino acid in the culture were assayed before (B) and 7 days after $(\mathrm{A})$ inoculation with $C$. difficile strain $\mathrm{N} 8$.

Table VII. Effect of addition of amino acid into the dialysed culture filtrate harvested after incubation of intestinal bacteria* on the growth of $C$. difficile strain $\mathrm{N} 8$

\begin{tabular}{|c|c|c|c|c|c|}
\hline \multirow{3}{*}{ Medium } & \multirow{2}{*}{\multicolumn{2}{|c|}{$\begin{array}{c}\text { Viable count of } \\
C . \text { difficile } \\
\left(\log _{10} \mathrm{cfu} / \mathrm{ml}\right)\end{array}$}} & \multicolumn{3}{|c|}{$\mathrm{pH}$} \\
\hline & & & \multirow{2}{*}{$0 \mathrm{~h}$} & \multirow{2}{*}{$24 \mathrm{~h}$} & \multirow{2}{*}{$48 \mathrm{~h}$} \\
\hline & $24 \mathrm{~h}$ & $48 \mathrm{~h}$ & & & \\
\hline GAM broth & $7 \cdot 1$ & $6 \cdot 8$ & 6.9 & $6 \cdot 1$ & $6 \cdot 4$ \\
\hline Dialysed culture filtrate $\dagger$ & $2 \cdot 0$ & $2 \cdot 1$ & $6 \cdot 3$ & $6 \cdot 2$ & $6 \cdot 1$ \\
\hline + aspartic acid & $2 \cdot 1$ & $2 \cdot 3$ & $6 \cdot 3$ & $6 \cdot 3$ & $6 \cdot 3$ \\
\hline + serine & $2 \cdot 0$ & $2 \cdot 1$ & $6 \cdot 3$ & $6 \cdot 1$ & $6 \cdot 2$ \\
\hline+ threonine & $2 \cdot 0$ & $2 \cdot 0$ & $6 \cdot 3$ & $6 \cdot 3$ & $6 \cdot \overline{3}$ \\
\hline+ arginine & $2 \cdot 1$ & $2 \cdot 1$ & $6 \cdot 3$ & $6 \cdot 5$ & $6 \cdot 4$ \\
\hline + asparagine & $2 \cdot 1$ & $2 \cdot 0$ & $6 \cdot 2$ & $6 \cdot 4$ & $6 \cdot 4$ \\
\hline+ mixture of five amino acids & $2 \cdot 1$ & $6 \cdot 0$ & $6 \cdot 3$ & $6 \cdot 3$ & $7 \cdot 4$ \\
\hline
\end{tabular}

* E. coli, Ent. avium, C. perfringens, C. ramosum, B. distasonis and Eu. lentum were inoculated into a dialysis bag containing $80 \mathrm{ml}$ of GAM broth. The dialysed culture filtrate $(120 \mathrm{ml})$ was collected 7 days after inoculation.

$\dagger$ Each amino acid was added into the dialysed culture filtrate to the same concentration as that in fresh GAM broth.

rulline nor ornithine affected the growth of $C$. difficile at all when added to GAM broth to the concentration detected in the mixed CF culture (data not shown). The concentrations of amino acids in mixed CF culture of either Ent. avium and E. coli, or C. perfringens,
K. pneumoniae and Ent. avium were not significantly different from those of the mixed structure of $C$. perfringens, Ent. avium and E. coli. Similar results were obtained when toxigenic $C$. difficile strain T-C-2 was used. 
Growth of $C$. difficile in the dialysed culture filtrate of faecal bacterial strains

To examine the effect of adding the deprived amino acids to the mixed CF culture (table VI), each amino acid (aspartic acid, serine, threonine, arginine and asparagine) was added to the outer dialysed culture filtrate. Although the addition of each amino acid individually did not restore the growth of $C$. difficile, the addition of all five amino acids resulted in a considerable growth of $C$. difficile after incubation for $48 \mathrm{~h}$ (table VII). Adjustment of the $\mathrm{pH}$ of the dialysed culture filtrate to 6.9 resulted in rapid growth of $C$. difficile after incubation for $24 \mathrm{~h}$ as did the use of fresh GAM broth (data not shown).

\section{Discussion}

C. difficile is frequently isolated from healthy infants. In this study the isolation rate was $c .65 \%$ in babies $<1$ year old, which was similar to those in previous reports. ${ }^{410-13}$ There have been many reports of the antagonistic effect of micro-organisms isolated from faeces on $C$. difficile. ${ }^{17-19}$ In these reports, the antagonistic aerobes included Pseudomonas aeruginosa, Staphylococcus aureus, Group D enterococci, Ent. faecalis, Ent. faecium, Streptococcus mitis and Streptococcus sp., and the antagonistic anaerobes included $C$. beijerinckii, Bacteroides sp., Bifidobacterium adolescentis, Bif. infantis, Bif. longum and Lactobacillus sp. However, these organisms were shown to be antagonistic to $C$. difficile in vitro when grown together on the surface of agar media. Wilson and Freter ${ }^{5}$ took advantage of CF culture, which can serve as a model of the ecology of large intestinal flora ${ }^{20}$ for an analysis of the interaction of $C$. difficile with hamster microflora. The entire faecal flora of the hamster suppressed the growth of $C$. difficile in the $\mathrm{CF}$ culture to $0.0002 \%$, whereas the suppression was only $10 \%$ when dissociated CF culture between $E$. coli and C. difficile was performed.

In the present study, the effects of both faecal flora and some combinations of faecal isolates on the growth of $C$. difficile were examined in $\mathrm{CF}$ culture. The growth of $C$. difficile strain N8 was inhibited more strongly in the $\mathrm{CF}$ culture with $C$. difficile-negative faeces than with $C$. difficile-positive faeces. Analysis of the faecal flora showed more intestinal species in $C$. difficile-negative infant faeces than in $C$. difficilepositive faeces. The total bacterial counts and counts of the predominant bacterial species such as Ent. avium, B. distasonis and Eu. lentum in the cultures of $C$. difficile-negative faeces were almost the same as those in the cultures of $C$. difficile-positive faeces. In addition to the effect of faecal flora, some combinations of faecal isolates were investigated for their inhibitory effect on the growth of C. difficile. Inhibition of growth was demonstrated in mixed CF culture with intestinal strains of Ent. avium, B. distasonis, Eu. lentum, C. ramosum, C. perfringens and either E. coli or
$K$. pneumoniae. The $\mathrm{pH}$ of the mixed $\mathrm{CF}$ culture was markedly decreased. Borriello and Barclay ${ }^{7}$ stated that, in most cases so far examined, the antagonism noted between various components of the faecal flora and $C$. difficile is attributable to the acidic conditions produced. However, it seems that mechanisms other than decreased $\mathrm{pH}$ might exist in the $\mathrm{CF}$ culture as there was no significant decrease in $\mathrm{pH}$ in the mixed $\mathrm{CF}$ culture with faecal flora (figs. 1 and 2).

In the $\mathrm{CF}$ cultures of $C$. difficile with the faecal flora of infants, the concentration of butyric acid and total VFAs of 10-day cultures after inoculation of $C$. difficile-negative faeces was higher than that after inoculation of $C$. difficile-positive faeces (data not shown). In the mixed CF culture of $C$. difficile with combinations of faecal isolates, inhibition of growth of $C$. difficile was correlated with the concentrations of acetic acid, propionic acid and total VFA in the CF culture before inoculation with $C$. difficile, but not with that of butyric acid. Rolfe ${ }^{21}$ reported that there was a direct correlation between the in-vitro inhibitory activity of the VFAs and the susceptibility of 4-day-old or older hamsters to intestinal colonisation of $C$. difficile when mixtures of VFA were prepared at concentrations equal to those present in the caeca of hamsters. In contrast, Su et al. ${ }^{22}$ showed that VFA could not inhibit intestinal colonisation by $C$. difficile in gnotobiotic mice associated with hamster intestinal flora. Similarly, Borriello and Barclay ${ }^{4}$ showed no correlation between the qualitative VFA analysis of faecal emulsion and the ability to inhibit growth of $C$. difficile in the in-vitro model. The results of this study show no significant correlation between the concentrations of VFAs and the inhibition of growth of $C$. difficile after inoculation of $C$. difficile into $\mathrm{CF}$ cultures. The limited growth of intestinal flora in the colonic ecosystem due to a lack of a carbon source has also been reported. ${ }^{23}$ It is reported that intestinal strains compete for various nutrients in $\mathrm{CF}$ culture, resulting in inhibition of growth of $C$. difficile as described previously. ${ }^{8}{ }^{24}$ Furthermore, the ecological mechanism of the suppressive effect of intestinal flora in cytotoxin production by $C$. difficile has been discussed. ${ }^{24}$

Haslam et al. ${ }^{25}$ studied the ability of several strains of $C$. difficile to grow in defined culture media and showed that proline, valine, leucine, iso-leucine and tryptophane were essential for growth of $C$. difficile. In this study, aspartic acid, citrulline, iso-leucine, leucine, proline, serine and threonine were shown to be utilised well by $C$. difficile strains. In the $\mathrm{CF}$ cultures that showed inhibition of growth of $C$. difficile, complete or almost complete consumption of several amino acids and significant increase of citrulline and ornithine were detected. It is possible that these changes in amino acid concentrations are associated with the inhibition of growth of $C$. difficile. Although the separate addition of each amino acid (aspartic acid, serine, threonine, arginine or asparagine) into the dialysed culture filtrate induced no increase in growth of $C$. difficile, either the 
addition of the mixture of the five amino acids or the adjustment of the $\mathrm{pH}$ of the filtrate to $6.9 \mathrm{did}$ (table VII). This also implies that there is no dialysable substance that is inhibitory to the growth of $C$. difficile. It is possible that culture conditions, including $\mathrm{pH}$ and the presence or absence of amino acids as nutrients, are associated with the inhibition of growth of $C$. difficile by faecal bacterial strains.

Interestingly, growth inhibition in the mixed $\mathrm{CF}$ culture of toxigenic $C$. difficile strains was much stronger than that in the mixed CF culture of non-

\section{References}

1. Fekety R, Silva J, Toshniwal $\mathrm{R}$ et al. Antibiotic associated colitis: effects of antibiotics on Clostridium difficile and the disease in hamsters. Rev Infect Dis 1979; 1 : 386-396.

2. Wilson KH, Silva J, Fekety FR. Suppression of Clostridium difficile by normal hamster cecal flora and prevention of antibiotic-associated cecitis. Infect Immun 1981; 34: 626-628.

3. Lyerly DM, Krivan HC, Wilkins TD. Clostridium difficile: its disease and toxins. Clin Microbiol Rev 1988; 1: 1-18.

4. Borriello SP, Barclay FE. Protection of hamsters against Clostridium difficile ileocaecitis by prior colonisation with non-pathogenic strains. $J$ Med Microbiol 1985; 19: 339-350.

5. Wilson KH, Freter R. Interaction of Clostridium difficile and Escherichia coli with microfloras in continuous-flow cultures and gnotobiotic mice. Infect Immun 1986; 54: $354-358$.

6. Wilson KH, Sheagren JN. Antagonism of toxigenic Clostridium difficile by nontoxigenic $C$. difficile. $J$ Infect Dis $1983 ; 147$ 733-736.

7. Borriello SP, Barclay FE. An in-vitro model of colonisation resistance to Clostridium difficile infection. J Med Microbiol 1986; 21 : 299-309.

8. Wilson KH, Perini F. Role of competition for nutrients in suppression of Clostridium difficile by the colonic microflora. Infect Immun 1988; 56: 2610-2614.

9. Gorbach SL, Chang T-W, Goldin B. Successful treatment of relapsing Clostridium difficile colitis with Lactobacillus GG. Lancet 1987; 2: 1519.

10. Viscidi R, Wiley S, Bartlett JG. Isolation rates and toxigenic potential of Clostridium difficile isolates from various patient populations. Gastroenterology 1981; 81 : 5-9.

11. Larson HE, Barclay FE, Honour P, Hill ID. Epidemiology of Clostridium difficile in infants. $J$ Infect Dis 1982; 146: 727-733.

12. Stark PL, Lee A, Parsonage BD. Colonization of the large bowel by Clostridium difficile in healthy infants: quantitative study. Infect Immun 1982; 35: 895-899.

13. Libby JM, Donta ST, Wilkins TD. Clostridium difficile toxin A in infants. $J$ Infect Dis 1983; 148: 606 .

14. Al-Jumaili IJ, Shibley M, Lishmann AH, Record CO. Incidence toxigenic strains. It was reported that toxigenic $C$. difficile was suppressed when a non-toxigenic strain was established first in the animal models. ${ }^{4.6}$ Seal et $a l .{ }^{26}$ administered a non-toxigenic strain of $C$. difficile to treat a case of relapse and to prevent further relapse in another patient, in both cases successfully. It is possible that the growth characteristics of $C$. difficile may differ in toxigenic and non-toxigenic strains.

This work was supported in part by a Grant-in-Aid for Scientific Research from the Ministry of Education, Science and Culture. and origin of Clostridium difficile in neonates. $J$ Clin Microbiol 1984; 19: 77-78.

15. Krivan HC, Clark GF, Smith DF, Wilkins TD. Cell surface binding site for Clostridium difficile enterotoxin: Evidence for a glycoconjugate containing the sequence $\mathrm{Gal} \alpha 1-3 \mathrm{Gal} \beta$ 1-4GlcNAc. Infect Immun 1986; 53: 573-581.

16. Nakamura S, Mikawa M, Nakashio $S$ et al. Isolation of Clostridium difficile from the feces of the antibody in sera of young and elderly adults. Microbiol Immunol 1981; 25: 345-351.

17. Rolfe RD, Helebian S, Finegold SM. Bacterial interference between Clostridium difficile and normal fecal flora. J Infect Dis 1981 ; 143 : 470-475.

18. Malamou-Ladas H, Tabaqchali S. Inhibition of Clostridium difficile by faecal streptococci. J Med Microbiol 1982; 15: $569-574$

19. Borriello SP, Barclay FE. In vitro inhibition of $C$. difficile. Eur $J$ Chemother Antibiot 1982; 2: 155-156.

20. Freter R, Stauffer E, Cleven D, Holdeman LV, Moore WEC. Continuous-flow cultures as in vitro models of the ecology of large intestinal flora. Infect Immun 1983; 39: 666-675.

21. Rolfe RD. Role of volatile fatty acids in colonization resistance to Clostridium difficile. Infect Immun 1984; 45: 185-191.

22. Su WJ, Waechter MJ, Bourlioux P, Dolegeal M, Fourniat J, Mahuzier G. Role of volatile fatty acids in colonization resistance to Clostridium difficile in gnotobiotic mice. Infect Immun 1987; 55: 1686-1691.

23. Freter $R$, Brickner $H$, Botney $M$, Cleven D, Aranki A. Mechanisms that control bacterial populations in continuous-flow culture models of mouse large intestinal flora. Infect Immun 1983; 39: 676-685.

24. Yamamoto T, Takahashi Y, Aiba Y, Ohnishi N, Ozawa A. Effect of Streptococcus parvulus and Peptostreptococcus magnus on cytotoxin levels of Clostridium difficile in anaerobic continuous flow culture. Microbiol Immunol $1987 ; 31$ : 949-958.

25. Haslam SC, Ketley JM, Mitchell TJ, Stephen J, Burdon DW, Candy DCA. Growth of Clostridium difficile and production of toxins A and B in complex and defined media. $J$ Med Microbiol 1986; 21 : 293-297.

26. Seal D, Borriello SP, Barclay F, Welch A, Piper M, Bonnycastle M. Treatment of relapsing Clostridium difficile diarrhoea by administration of a non-toxigenic strain. Eur $J$ Clin Microbiol 1987; 6: 51-53. 